Subscriber access provided by Caltech Library

\title{
Perspective
}

\section{Data Acquisition Protocols and Reporting Standards for Studies of the Electrochemical Reduction of Carbon Dioxide}

Ezra L. Clark, Joaquin Resasco, Alan Landers, John Lin, Linh-Thao Chung, Amber Walton, Christopher Hahn, Thomas F. Jaramillo, and Alexis T. Bell

ACS Catal., Just Accepted Manuscript • DOI: 10.1021/acscatal.8b01340 • Publication Date (Web): 01 Jun 2018

Downloaded from http://pubs.acs.org on June 4, 2018

\section{Just Accepted}

"Just Accepted" manuscripts have been peer-reviewed and accepted for publication. They are posted online prior to technical editing, formatting for publication and author proofing. The American Chemical Society provides "Just Accepted" as a service to the research community to expedite the dissemination of scientific material as soon as possible after acceptance. "Just Accepted" manuscripts appear in full in PDF format accompanied by an HTML abstract. "Just Accepted" manuscripts have been fully peer reviewed, but should not be considered the official version of record. They are citable by the Digital Object Identifier (DOI@). "Just Accepted" is an optional service offered to authors. Therefore, the "Just Accepted" Web site may not include all articles that will be published in the journal. After a manuscript is technically edited and formatted, it will be removed from the "Just Accepted" Web site and published as an ASAP article. Note that technical editing may introduce minor changes to the manuscript text and/or graphics which could affect content, and all legal disclaimers and ethical guidelines that apply to the journal pertain. ACS cannot be held responsible for errors or consequences arising from the use of information contained in these "Just Accepted" manuscripts. 


\title{
Standards and Protocols for Data Acquisition and Reporting for Studies of the Electrochemical Reduction of Carbon Dioxide
}

\author{
Ezra L. Clark ${ }^{\dagger 1,2}$, Joaquin Resasco ${ }^{\dagger 1,2}$, Alan Landers ${ }^{3,5}$, John Lin ${ }^{4,5}$, Linh-Thao Chung ${ }^{2}$, Amber \\ Walton $^{2}$, Christopher Hahn ${ }^{4,5}$, Thomas F. Jaramillo ${ }^{4,5}$, Alexis T. Bell ${ }^{1,2 *}$ \\ $\dagger$ These authors contributed equally \\ 1. Joint Center for Artificial Photosynthesis \\ Lawrence Berkeley National Laboratory \\ Berkeley, CA 94720
}

2. Department of Chemical and Biomolecular Engineering

University of California

Berkeley, CA 94720

3. Department of Chemistry

Stanford University

Stanford, CA 94305

4. Department of Chemical Engineering

Stanford University

Stanford, CA 94305

5. SUNCAT Center for Interface Science and Catalysis

Stanford University, Stanford, CA 94305

SLAC National Accelerator Laboratory

Menlo Park, CA 91125

\author{
Submitted to \\ ACS Catalysis \\ *To whom correspondence should be sent: alexbell@,berkeley.edu




\begin{abstract}
Objective evaluation of the performance of electrocatalysts for $\mathrm{CO}_{2}$ reduction has been complicated by a lack of standardized methods for measuring and reporting activity data. In this perspective, we advocate that standardizing these practices can aid in advancing research efforts toward the development of efficient and selective $\mathrm{CO}_{2}$ reduction electrocatalysts. Using information taken from experimental studies, we identify variables that influence the measured performance of $\mathrm{CO}_{2}$ reduction electrocatalysts and propose procedures to improve the accuracy and reproducibility of reported data. We recommend that catalysts be measured under conditions which do not introduce artifacts from impurities, either from the electrolyte or counter electrode, and advocate the acquisition of data measured in the absence of mass transport effects. Furthermore, measured rates of electrochemical reactions should be normalized to both the geometric electrode area as well as the electrochemically active surface area to facilitate the comparison of reported catalysts with those previously known. We demonstrate that when these factors are accounted for, the $\mathrm{CO}_{2}$ reduction activity of $\mathrm{Ag}$ and $\mathrm{Cu}$ measured in different laboratories exhibit little difference. Adoption of the recommendations presented in this perspective would greatly facilitate the identification of superior catalysts for $\mathrm{CO}_{2}$ reduction arising solely from changes in their composition and pretreatment.
\end{abstract}

\author{
Keywords \\ Electrocatalysis, $\mathrm{CO}_{2}$ reduction, experimental protocols, catalyst benchmarking, mass \\ transfer effects, surface contamination, surface area normalization, intrinsic activity metrics
}


Table of Contents Graphic

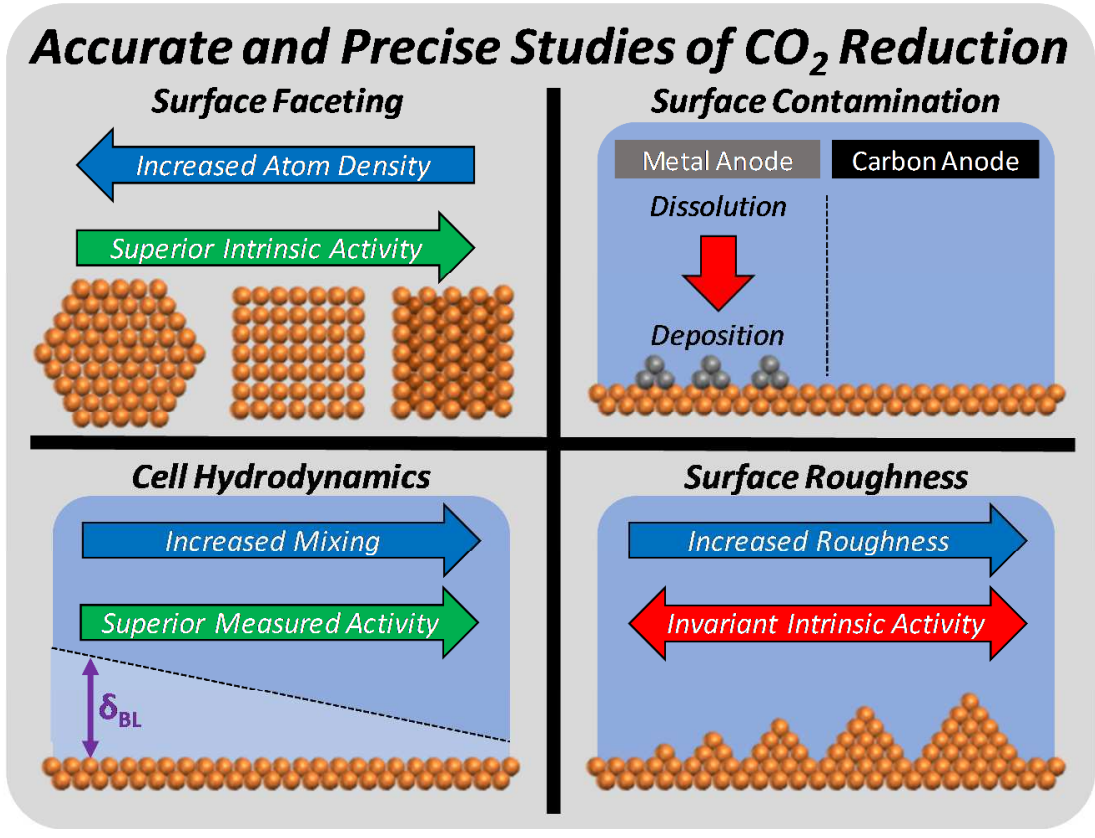




\section{Introduction}

The electrochemical reduction of $\mathrm{CO}_{2}$ offers a means of producing transportation fuels and commodity chemicals using intermittent renewable electricity. ${ }^{1-3}$ Motivated by this objective, numerous publications have appeared in recent years aimed at identifying electrocatalysts that can efficiently and selectively reduce $\mathrm{CO}_{2}$ to desired products. ${ }^{4-10}$ However, objective evaluation of the activity and selectivity of different catalysts and operating conditions has proven difficult due to a lack of standardized protocols for preparing catalysts and evaluating their electrocatalytic activity. These issues are significant because the performance of electrocatalyts is influenced not only by the composition and morphology of the electrocatalyst itself, but also by the composition of the electrolyte, the hydrodynamics of the electrochemical cell, and the purity of both the electrocatalyst and the electrolyte.

This perspective identifies some of the key variables that influence the measured activity and selectivity of $\mathrm{CO}_{2}$ reduction electrocatalysts with the aim of proposing procedures to obtain reproducible data that can be attributed solely to properties of the catalyst. We show how each factor affects the measured electrocatalytic activity and selectivity and provide recommendations for the preparation of electrocatalysts and the design of electrochemical cells. We demonstrate that interinstitutional reproducibility is observed over independently prepared and tested catalyst materials when these recommendations are considered. Finally, we stress the importance of reporting electrocatalyst activity normalized by the electrochemically active surface area and caution against claims of superior catalyst performance based solely on Faradaic efficiency.

\section{Benchmarking Electrocatalytic Performance}


Comparing catalytic data from different laboratories can be convoluted because each tends to use its own sources of catalyst and electrolyte, method of catalyst preparation and pretreatment, and design of the electrochemical cell used for catalyst evaluation. As we show below, these differences can introduce unintended consequences that impact the observed activity of $\mathrm{CO}_{2}$ reduction electrocatalysts. To minimize the effects of factors other than catalyst composition and morphology, we recommend that research groups benchmark their ability to accurately and consistently reproduce the published activity for a well-studied planar monometallic catalyst prior to reporting data for new catalysts.

The choice of electrocatalyst to be used for benchmarking purposes requires careful consideration. $\mathrm{Cu}$ is the most well studied catalyst for $\mathrm{CO}_{2}$ reduction because it is the only monometallic catalyst that can reduce $\mathrm{CO}_{2}$ to hydrocarbons and alcohols with reasonably high Faradaic efficiencies. ${ }^{11-14}$ However, it should be noted that $\mathrm{Cu}$ produces a wide variety of products, the distribution of which is sensitive to the manner of catalyst preparation. To illustrate this point, the $\mathrm{CO}_{2}$ reduction activity observed over $\mathrm{Cu}(111)$ and $\mathrm{Cu}(100)$ are compared in Figure 1a. ${ }^{13,15,16}$ Experimental details of the preparation and testing of these epitaxial thin films can be found in the Supporting Information (see SI-1 and SI-2). The Cu(100) surface exhibits an activity for generating $\mathrm{C}_{2+}$ products roughly an order of magnitude higher than that for $\mathrm{Cu}(111)$, as reported elsewhere. ${ }^{13,16}$ This facet dependence can cause polycrystalline $\mathrm{Cu}$ foils obtained from different vendors or even different batches from the same vendor to exhibit large differences in electrocatalytic activity and selectivity that arise due to variations in surface faceting. In contrast to $\mathrm{Cu}, \mathrm{Ag}$ predominately produces $\mathrm{H}_{2}$ and $\mathrm{CO}$, with $\mathrm{CO}$ Faradaic efficiencies exceeding $90 \%$ at an applied potential of $-1 \mathrm{~V}$ vs RHE. ${ }^{17,18}$ Furthermore, the product distribution obtained over $\mathrm{Ag}$ is less facet-dependent than that observed over $\mathrm{Cu}^{17}$ To illustrate 
this point the $\mathrm{CO}_{2}$ reduction activity of $\mathrm{Ag}(111)$ and $\mathrm{Ag}(100)$ are compared in Figure $1 \mathrm{~b}$. While the $\mathrm{CO}$ evolution activity exhibits a slight facet dependence, the variation observed is only a factor of $\sim 2$. The relatively similar activity observed over $\operatorname{Ag}(111)$ and $\operatorname{Ag}(100)$ means that the activity observed over polycrystalline Ag foils will exhibit less variation from sample to sample. Thus, we recommend that Ag be used as a benchmarking electrocatalyst to assess the ability of a research group to carry out accurate and reproducible activity measurements. 
a
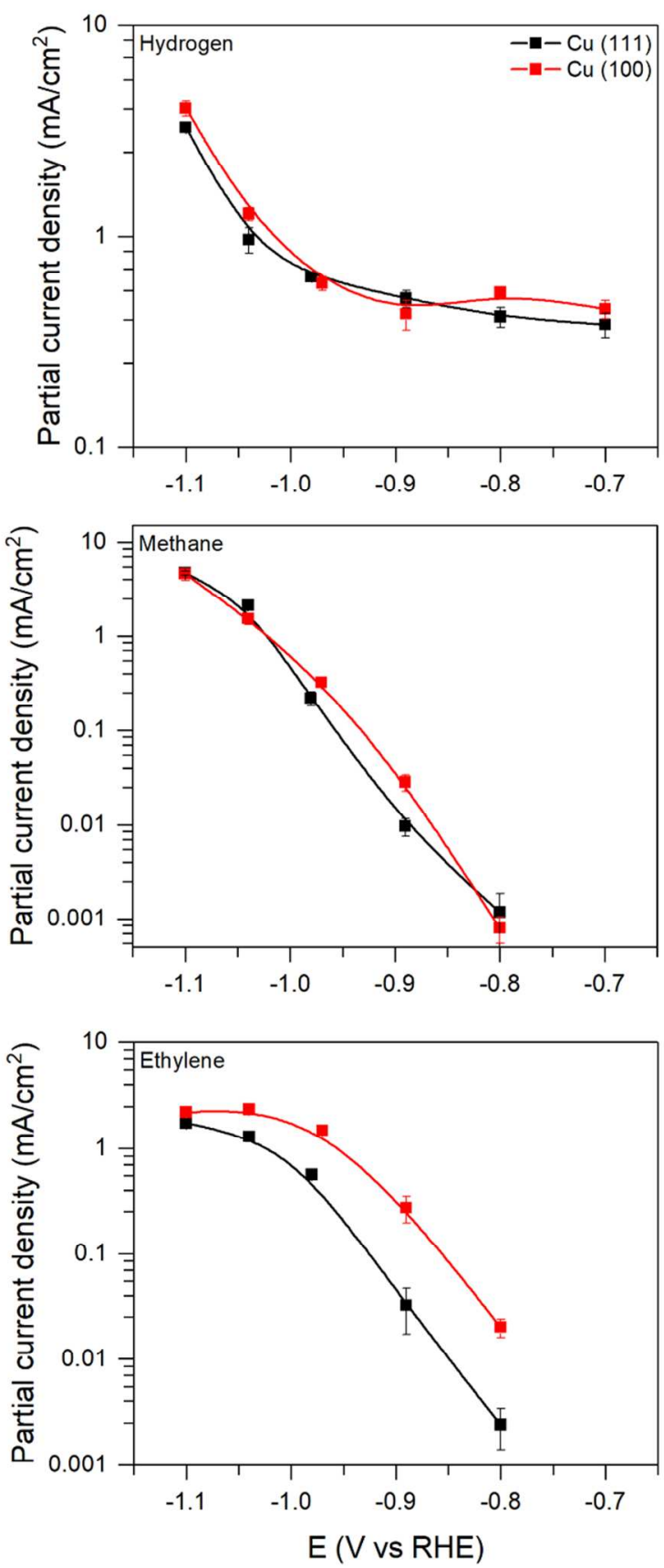

b
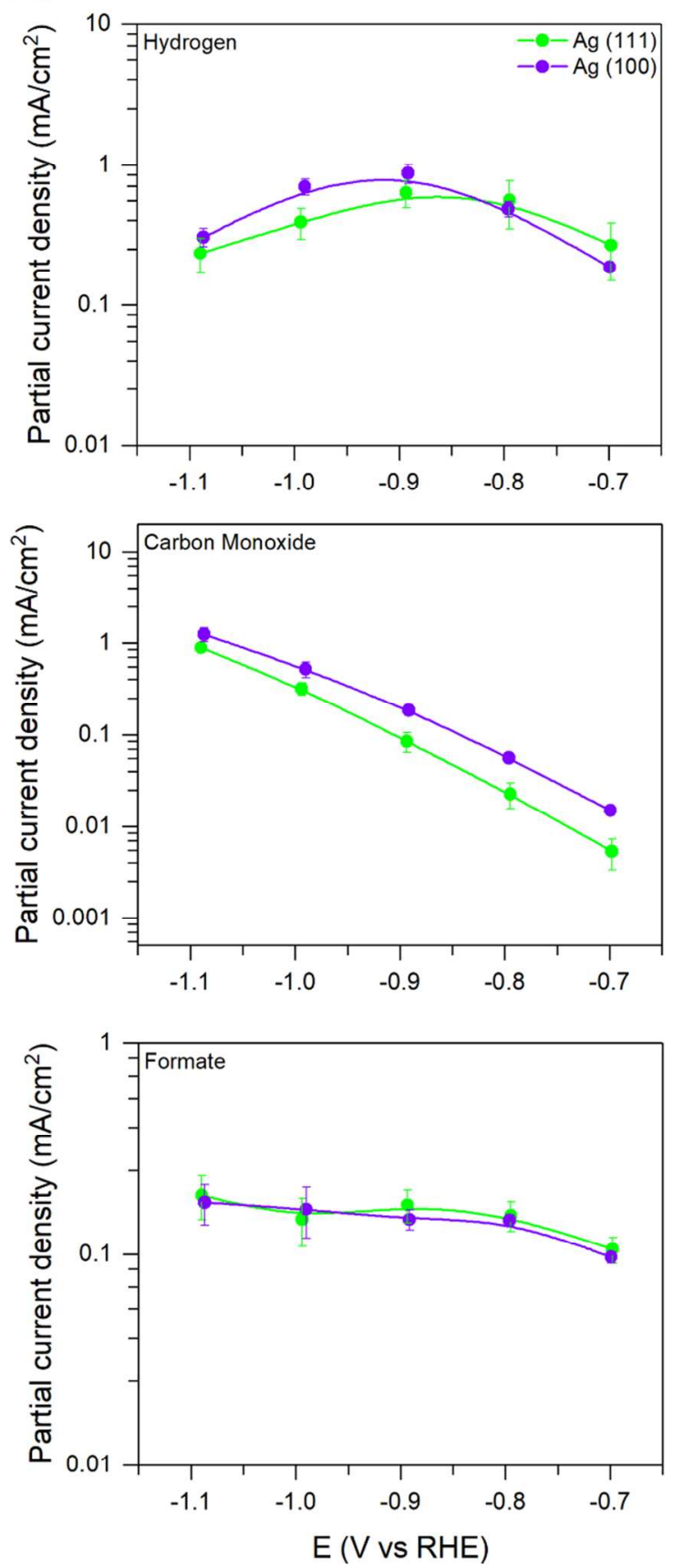

Figure 1: Structure sensitivity of $\mathbf{C u}$ and Ag-based catalysts. Electrochemical $\mathrm{CO}_{2}$ reduction experiments performed over epitaxial thin films in $0.1 \mathrm{M} \mathrm{KHCO}_{3}$ : a) $\mathrm{Cu}(111)$ vs $\mathrm{Cu}(100)$. Activity toward ethylene production shows strong facet dependence. b) $\operatorname{Ag}(111) \mathrm{vs} \operatorname{Ag}(100)$ show similar activity toward $\mathrm{CO}$ formation.

Surface preparation methods can also introduce additional variations in activity and selectivity between samples of the same metal due to the impact that these pretreatments have on 
the purity and distribution of facets at the electrode surface. ${ }^{19,20}$ Mechanical polishing can introduce contaminants onto the catalyst surface from the polish residue (see SI-3). These polish residues can be susceptible to electrochemical reduction under the conditions of $\mathrm{CO}_{2}$ reduction and may exhibit background activity in the metallic state, as is the case for alumina-based polishing compounds. ${ }^{21}$ As a result, $\mathrm{SiC}$ and diamond-based polishing compounds should be favored over alumina-based polishing compounds since residues from these compounds will be largely electrochemically inert. Electropolishing can also be utilized but thorough rinsing of the electrocatalyst should be practiced to prevent carryover of specifically adsorbing anions into the reaction vessel.

Comparisons between different catalysts should only be done if their activity was measured in identical electrolyte solutions. Several studies have demonstrated that the identity of the cations and anions in the electrolyte affect both the activity and selectivity of $\mathrm{CO}_{2}$ reduction catalysts. For example, the activity and selectivity of both polycrystalline foils and epitaxial thin films of $\mathrm{Ag}$ and $\mathrm{Cu}$ have been demonstrated to change as the size of the electrolyte cation is increased from $\mathrm{Li}^{+}$to $\mathrm{Cs}^{+} \cdot{ }^{22}$ Larger cations, such as $\mathrm{Cs}^{+}$, favor the formation of $\mathrm{CO}$ over Ag and $\mathrm{C}_{2+}$ products over $\mathrm{Cu}$ due to electrostatic field-stabilization of species involved in the formation of $\mathrm{CO}$ in the case of $\mathrm{Ag}$ and of $\mathrm{C}-\mathrm{C}$ bonds, such as adsorbed $\mathrm{OCCO}$ and $\mathrm{OCCHO}$, in the case of Cu. ${ }^{23}$ Conversely, cation size has no effect on the partial current densities for $\mathrm{H}_{2}$ or $\mathrm{CH}_{4}$ because their mechanistic pathways do not involve reaction intermediates with significant dipole moments and there are insignificant changes in the dipole moment between the reactant and transition state. ${ }^{23}$ The composition of the anionic component of the supporting electrolyte can also affect $\mathrm{CO}_{2}$ reduction selectivity. For example, in the case of $\mathrm{CO}_{2}$ reduction over $\mathrm{Cu}$, phosphate-based electrolytes result in higher partial currents for $\mathrm{H}_{2}$ and $\mathrm{CH}_{4}$ than are observed in 
bicarbonate-based electrolytes, but the choice electrolyte anion has little effect on the partial currents for $\mathrm{CO}, \mathrm{HCOO}^{-}, \mathrm{C}_{2} \mathrm{H}_{4}$, or $\mathrm{C}_{2} \mathrm{H}_{5} \mathrm{OH}$. Furthermore, changes in the buffer concentration also impact catalyst selectivity. ${ }^{24-27}$ As a result of these influences, researchers should only compare catalytic data obtained using identical electrolyte solutions. Obtaining catalytic data in either $0.1 \mathrm{M} \mathrm{KHCO}_{3}$ or $0.1 \mathrm{M} \mathrm{CsHCO}_{3}$ will enable the greatest comparison to published catalytic data, since the majority of $\mathrm{CO}_{2}$ reduction studies have been conducted using these electrolytes.

\section{Impact of Electrochemical Cell Hydrodynamics on Electrocatalytic Activity}

The electrochemical reduction of $\mathrm{CO}_{2}$ is highly susceptible to concentration polarization, wherein Faradaic processes induce concentration gradients near the electrode surface. These concentration gradients arise because bicarbonate solutions are weak buffers and $\mathrm{CO}_{2}$ has a low mass transfer coefficient through aqueous solutions. ${ }^{28,29}$ Even modest current densities cause the $\mathrm{pH}$ and $\mathrm{CO}_{2}$ concentration near the cathode surface to vary significantly from that in the bulk electrolyte. ${ }^{30,31}$ The magnitude of the concentration gradients depends largely on the hydrodynamics of the electrochemical cell. As a result, the electrolyte needs to be mixed vigorously to ensure sufficient mass transport to and from the cathode. Electrolyte mixing in small electrochemical cells is usually accomplished by agitation of the electrolyte with a column of $\mathrm{CO}_{2}$ bubbles, although pump-driven recirculation of $\mathrm{CO}_{2}$-saturated electrolyte has also been employed. ${ }^{32,33}$ Activity data acquired in a regime where significant concentration polarization occurs does not reflect the intrinsic activity or selectivity of the catalyst, but rather the convolution of the properties of the catalyst and the effects of mass transfer. Therefore, researchers should avoid measuring catalytic activity under conditions where mass transfer effects are significant because correcting for these effects is nontrivial. Researchers should also 
only consider the portion of their data that has been shown to be free of the effects of mass transfer when making conclusions about intrinsic reaction kinetics.

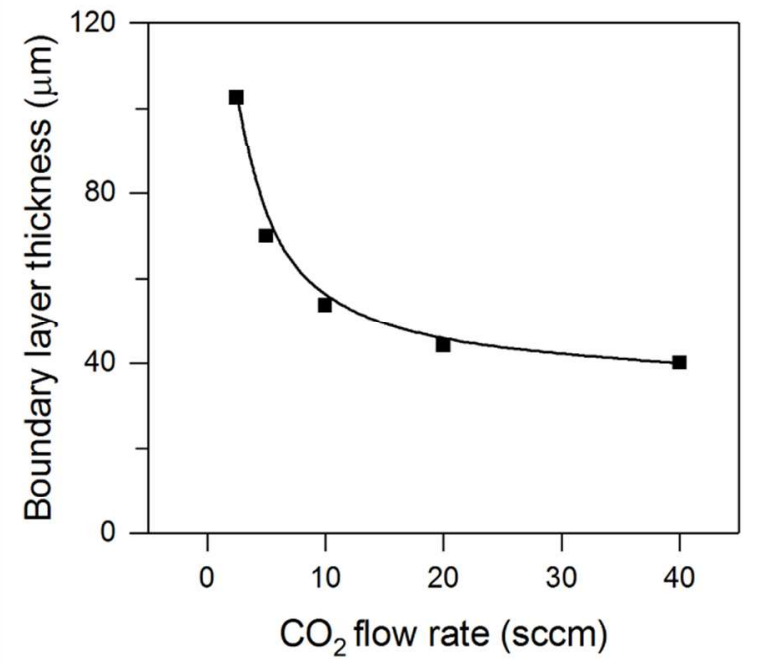

Figure 2: Quantifying the cathodic hydrodynamic boundary layer thickness. Hydrodynamic boundary layer thicknesses at the cathode surface calculated by measuring the diffusion limited current density of ferricyanide reduction over polycrystalline $\mathrm{Au}$ as a function of the $\mathrm{CO}_{2}$ flow rate utilized to mix the catholyte.

The mass transfer boundary layer thickness of an electrochemical cell can be quantified by measuring the diffusion-limited current density for ferricyanide reduction (see SI-4). As shown in Figure 2, increasing the $\mathrm{CO}_{2}$ flow rate reduces the hydrodynamic boundary layer thickness but has a diminishing effect as the $\mathrm{CO}_{2}$ flow rate is increased. Activity measurements were conducted as a function of the applied potential for different $\mathrm{CO}_{2}$ flow rates to demonstrate the impact that the mass transfer boundary layer thickness has on the measured activity of polycrystalline Ag. Figure 3 shows the partial current densities for $\mathrm{H}_{2}$ and $\mathrm{CO}$ as a function of the mass transfer boundary layer thickness, which was systematically varied by varying the $\mathrm{CO}_{2}$ flow rate through the cell. The variation in the partial currents for $\mathrm{H}_{2}$ and $\mathrm{CO}$ are direct results of the variation in the mass transfer boundary layer thickness at the cathode surface and is not due to changes in the bulk $\mathrm{CO}_{2}$ concentration. The latter statement is supported by the observation 
that electrochemical cells incorporating gas dispersion frits maintain saturation of the bulk electrolyte with $\mathrm{CO}_{2}$ during prolonged electrolysis. ${ }^{32}$

We note that the tested Ag films were completely free of contaminants within the detection limits of XPS and LEIS (see SI-5). Thus, the observed variations in electrocatalytic activity are a direct result of the degree to which concentration polarization influences the observed electrocatalytic activity. As shown in Figure 3, the hydrodynamic regime in which the activity of polycrystalline Ag is measured dictates what is observed at potentials more negative than $-1 \mathrm{~V}$ vs RHE, the potential for which mass transfer effects become significant (see SI-6). As the hydrodynamic boundary layer thickness is reduced, less $\mathrm{H}_{2}$ and more $\mathrm{CO}$ is produced at a given applied potential, resulting in a CO Faradaic efficiency swing of $\sim 60 \%$ at $-1.4 \mathrm{~V}$ vs RHE. As a result, the maximum rate of $\mathrm{CO}_{2}$ consumption over the cathode increases inversely with the hydrodynamic boundary layer thickness, as expected for a diffusion-limited process (see SI-6). 
a

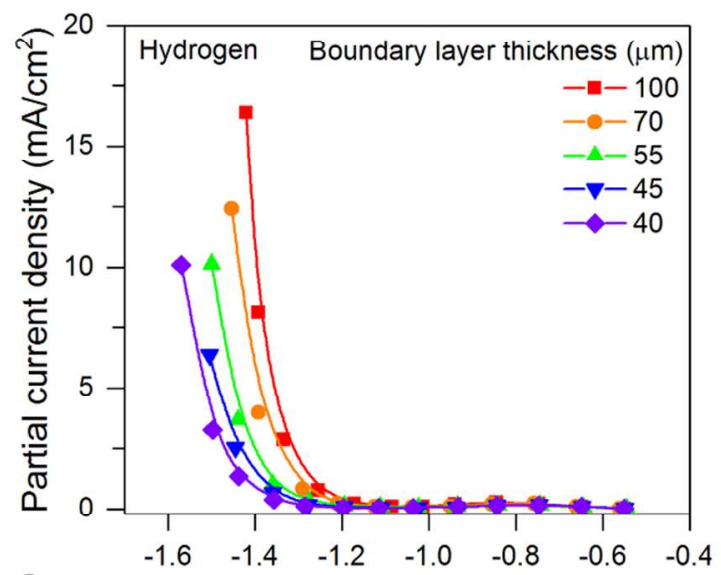

C

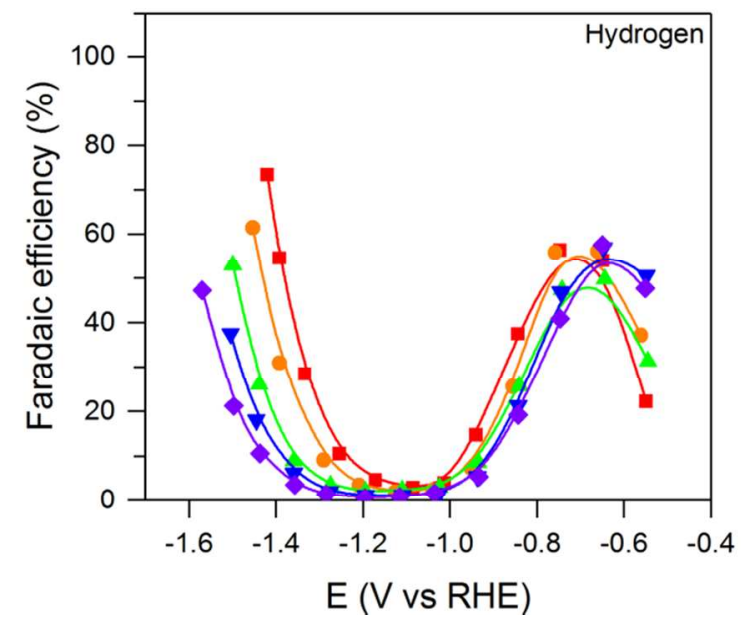

b
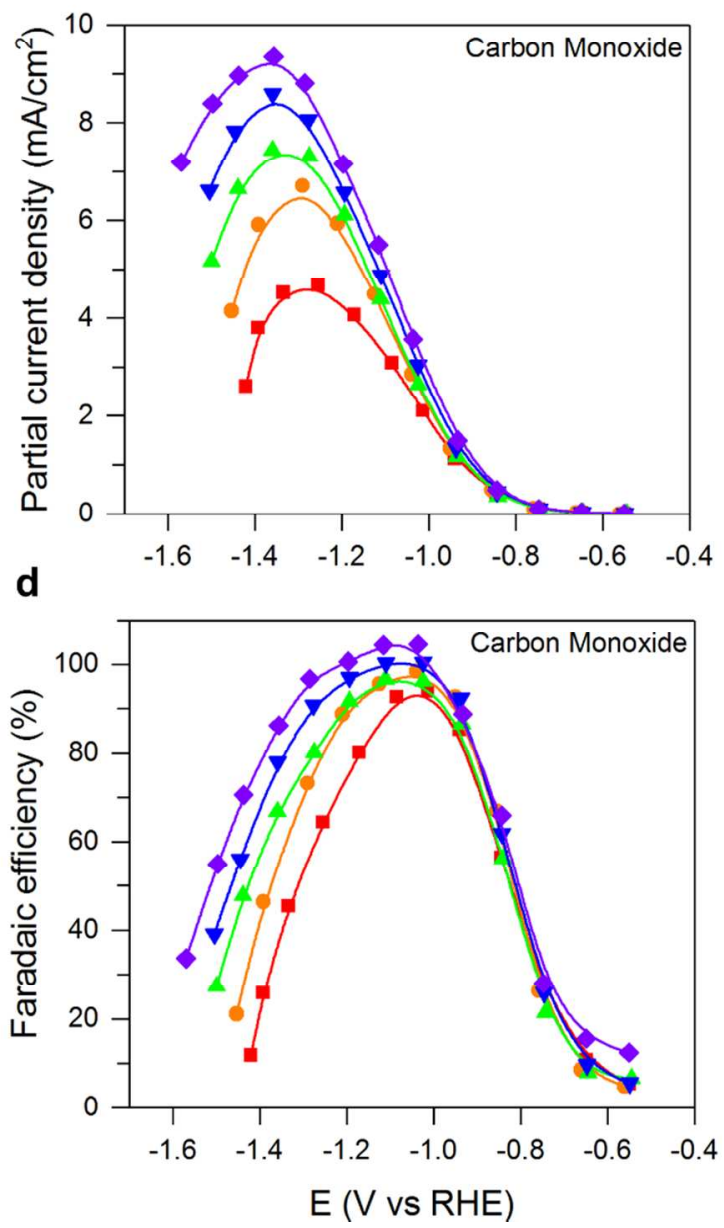

Figure 3: Dependence of the measured activity of polycrystalline Ag on the hydrodynamics of the electrochemical cell achieved by varying the $\mathrm{CO}_{2}$ flow rate utilized to mix the catholyte. a) $\mathrm{H}_{2}$ partial current density. b) $\mathrm{CO}$ partial current density. c) $\mathrm{H}_{2}$ Faradaic efficiency. d) CO Faradaic efficiency.

This demonstration of the influence of the hydrodynamics of the electrochemical cell on the measured activity of polycrystalline Ag indicates the importance of designing electrochemical cells with adequate electrolyte mixing and conducting catalytic activity measurements in a regime that is minimally influenced by mass transfer to the cathode surface. Only under such conditions is it possible to definitively measure the intrinsic activity of the catalyst and obtain data that is directly comparable across research institutions. For the 
electrochemical cell and polycrystalline Ag catalyst utilized here, the impact of concentration polarization becomes significant for applied potentials below $-1 \mathrm{~V}$ vs RHE, as indicated by the deviation of the CO partial current density from Tafel kinetics (see SI-6). As a result, the measured activity is minimally affected by the mass transfer boundary layer thickness at potentials more positive than $-1 \mathrm{~V}$ vs RHE. It should be noted, though, the potential at which concentration polarization becomes significant is a function of the overall current density and not the applied potential. As a result, catalysts with high surface areas are more susceptible to mass transfer limitations than planar catalysts, which complicates obtaining an accurate measurement of their intrinsic activity. Another point to realize is that concentration polarization introduces error when reporting data on a RHE scale because the local $\mathrm{pH}$ deviates substantially from that in the bulk, as shown in Figure $4 .{ }^{34}$ This error can become significant when comparing catalysts that suffer from concentration polarization to different extents. Examples include comparing catalysts with vastly different surface roughness or comparing planar catalysts evaluated in electrochemical cells with different hydrodynamic boundary layer thicknesses. ${ }^{35}$ These differences can lead to divergent local reaction environments that convolute accurate activity comparisons. 


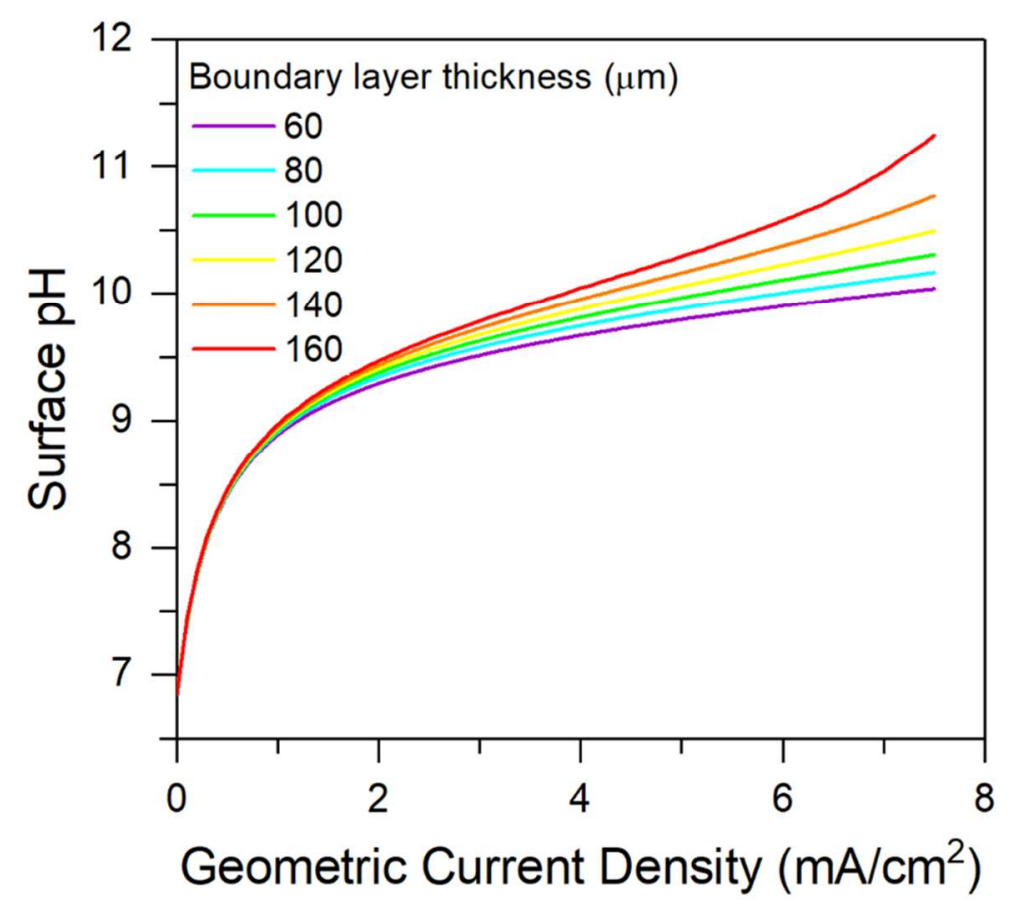

Figure 4: Calculated surface $\mathrm{pH}$ as a function of the geometric current density and the hydrodynamic boundary layer thickness.

\section{III: Impact of Impurities on Electrocatalytic Activity}

The steady-state activity and selectivity of a material should be measured in the absence of surface contamination to assess its intrinsic catalytic properties. If surface contamination occurs, it is important to distinguish whether it is a consequence of catalytic intermediates that poison the surface or whether it is the result of impurities inadvertently introduced onto the surface. ${ }^{36}$ We note that the high overpotentials typically utilized to evaluate the activity of $\mathrm{CO}_{2}$ reduction electrocatalysts are sufficiently negative to reduce nearly any transition metal cation that might be present in the catholyte. In general, transition metal impurities will increase the activity of the electrocatalyst for the $\mathrm{H}_{2}$ evolution reaction (HER), since the late transition and pblock metals typically studied as $\mathrm{CO}_{2}$ reduction electrocatalysts have very low HER activity. ${ }^{37,38}$ Even trace quantities $(<1 \mu \mathrm{M})$ of transition metal cations in the electrolyte can cause $\mathrm{CO}_{2}$ reduction electrocatalysts to lose their activity on the timescale of a typical experiment. ${ }^{38,39}$ 
Metallic impurities in the catholyte can originate from the solvent, the electrolyte salts, and from the other components of the electrochemical cell.

The purity of the electrode surface is often validated using X-ray photoelectron spectroscopy (XPS). This analytical method probes the composition of the top 0.5 to $2 \mathrm{~nm}$ of the sample, depending on the collection angle and the kinetic energy of the relevant photoelectrons. $^{40}$ The detection limit of XPS for transition metals is typically between 0.1 and 1 atomic percent, depending on the sample morphology and the combination of elements. ${ }^{41}$ While this detection limit may be adequate for certain applications, it is inadequate for validating the purity of catalyst surfaces since even $\sim 20 \%$ of a monolayer of impurities can go undetected by XPS. $^{40,41}$ Thus, the lack of observable contamination by XPS does not indicate that the electrode surface is free of contamination. Low-energy ion scattering (LEIS) spectroscopy, also called ion scattering spectroscopy (ISS) can be used to more accurately validate the purity of the catalyst surface since it only probes the top layer of atoms on the sample surface. ${ }^{42}$ However, because LEIS is a line-of-sight technique it can be difficult to obtain quantitative information about the relative abundance of constituent elements due to their nonequivalent coverage by adventitious adsorbates, such as ambient oxygen. Despite this, ISS is a very useful analytical technique because of its enhanced sensitivity for detecting impurities on an electrode surface.

Researchers have recently demonstrated that Pt and other noble metals typically used as anode electrocatalysts can dissolve under typical operating conditions. ${ }^{43-48}$ The transition metal cations evolved from the anode can reach the cathode even when an anion exchange membrane is utilized to separate the electrode chambers. ${ }^{49}$ Whether this crossover occurs during operation or during the storage and cleaning of the electrochemical cell has yet to be resolved conclusively. The effect of inadvertent $\mathrm{Pt}$ contamination on the activity of $\mathrm{Cu}(100)$ is shown in Figure 5, which 
compares the transient activity observed over $\mathrm{Cu}(100)$ when $\mathrm{Pt}$ and glassy carbon (GC) are employed as anodes. Figure 5a shows that the activity for producing $\mathrm{H}_{2}$ and $\mathrm{C}_{2} \mathrm{H}_{4}$ increase and decrease, respectively, over the course of $1 \mathrm{hr}$ when Pt is used as the anode. However, Figure 5b shows that the activity for all products is remarkably stable when GC is used as the anode. While both surfaces appeared to be free of contamination by XPS, Pt was detected by LEIS on the $\mathrm{Cu}(100)$ electrode tested using a Pt anode. Thus, researchers should employ a sacrificial GC anode when measuring the intrinsic activity of $\mathrm{CO}_{2}$ reduction electrocatalysts to prevent inadvertent surface contamination.
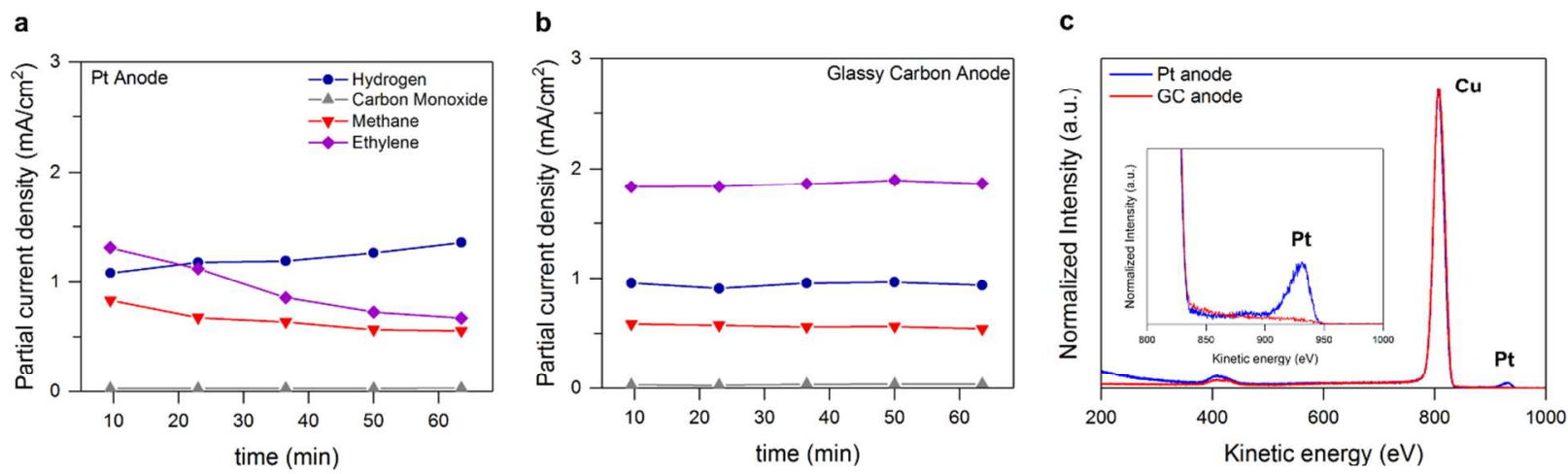

Figure 5: Effect of the counter electrode on transient activity. Comparison of the transient activity observed over $\mathrm{Cu}(100)$ at an applied potential of $-1.0 \mathrm{~V}$ vs $\mathrm{RHE}$ in $0.1 \mathrm{M} \mathrm{KHCO}_{3}$ : a) using a Pt anode and b) using a GC anode. c) Comparison of the LEIS spectra of $\mathrm{Cu}(100)$ tested using Pt and GC anodes. The presence of Pt is observed on the surface only when $\mathrm{Pt}$ is used as the anode.

The degree to which impurities impact the observed activity depends strongly on the surface area of the cathode relative to the volume of the catholyte. Since the cathodic potential needed to drive $\mathrm{CO}_{2}$ reduction is usually much more negative than the standard reduction potential of transition metal cations, it can be assumed that over a long period of time most of the metal impurities present in the electrolyte will be electrodeposited onto the cathode surface. Figure 6 demonstrates that even very small concentrations $(<1 \mu \mathrm{M})$ of electrolyte impurities can 
result in a significant coverage (0.1 ML) on the electrocatalyst surface (see SI-7). Furthermore, the calculation indicates that contamination will be especially problematic for systems where the catholyte volume is large compared to the electrode surface area. This means that the tolerance for impurities increases with the roughness of the catalyst surface. Therefore, researchers should be mindful of the different extents to which impurities could influence the observed activity when comparing two catalysts with significantly different roughness factors. For instance, lower rates of HER over a high surface area catalyst in comparison to a low surface area standard could potentially be the result of a smaller fraction of surface sites being covered by electrodeposited impurities.

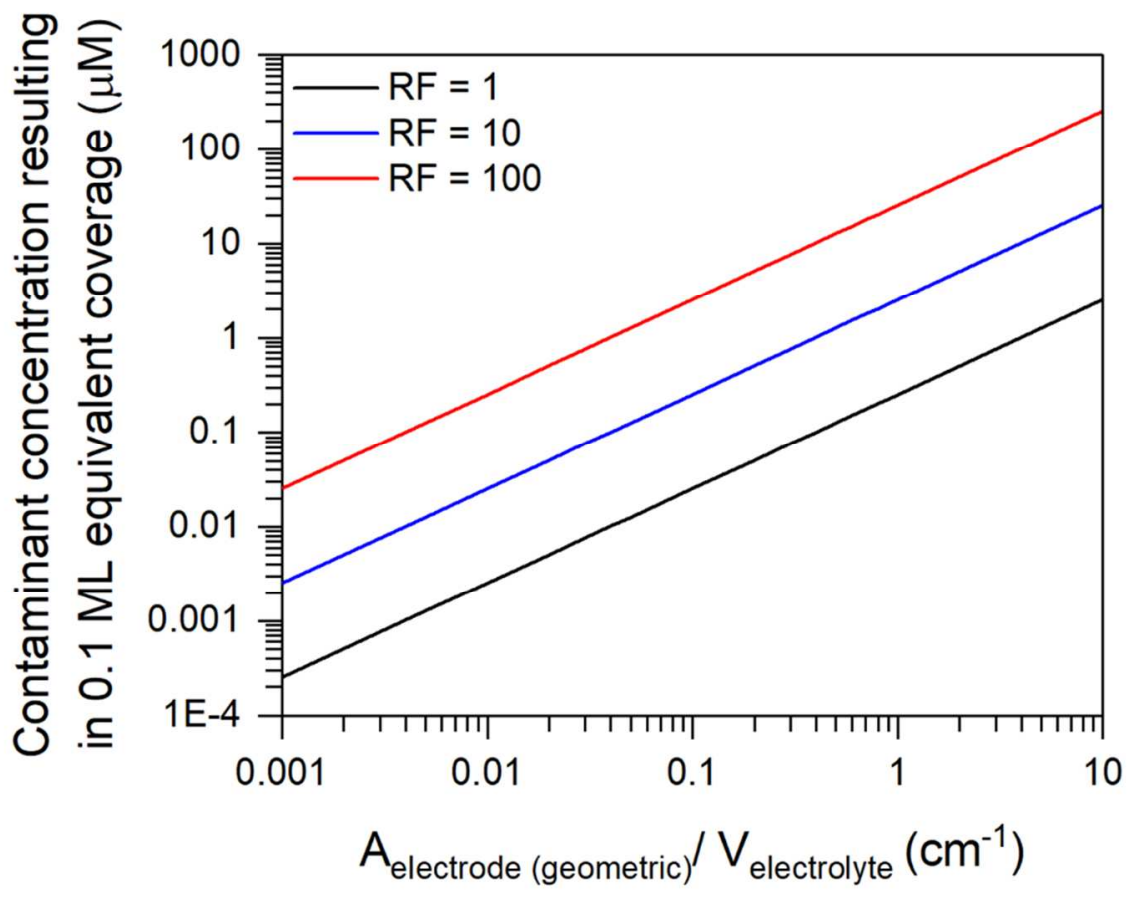

Figure 6: Factors affecting the impact of electrolyte impurities. Electrolyte impurity concentration required to cover $10 \%$ of the electrocatalyst surface based on the geometric cathode surface area to catholyte volume ratio and the roughness factor of the cathode surface.

\section{IV: Interinstitutional Reproducibility}


Consistent and reproducible reports of $\mathrm{CO}_{2}$ reduction electrocatalysis are critical to advancing the field. By first benchmarking electrochemical systems against standard catalysts researchers can be assured that results obtained from testing a novel catalyst formulation will be repeatable at other institutions and that measured activity can be confidently attributed to the properties of the catalyst itself. The entire electrochemical system, including catalyst, electrolyte, electrochemical cell, and operating conditions, needs to be considered before making comparisons with the literature.

With careful experimentation, electrocatalyst activity can be accurately and reliably reproduced at different academic institutions. This point is nicely illustrated by the data presented in Figure 7, which shows the activity for selected products obtained over polycrystalline silver and epitaxial $\mathrm{Cu}(100)$ thin films, prepared and tested independently at Berkeley and Stanford. Similar experimental protocols were used at both institutions to avoid artifacts from impurities, and a potential range was chosen for comparison in which the effects of concentration polarization were minimized. Further details of the cell design and experimental protocols at each institution are included in the Supporting Information (see SI-1 and SI-2). The close agreement in observed activity demonstrates that reproducibility can be achieved with careful experimentation. 

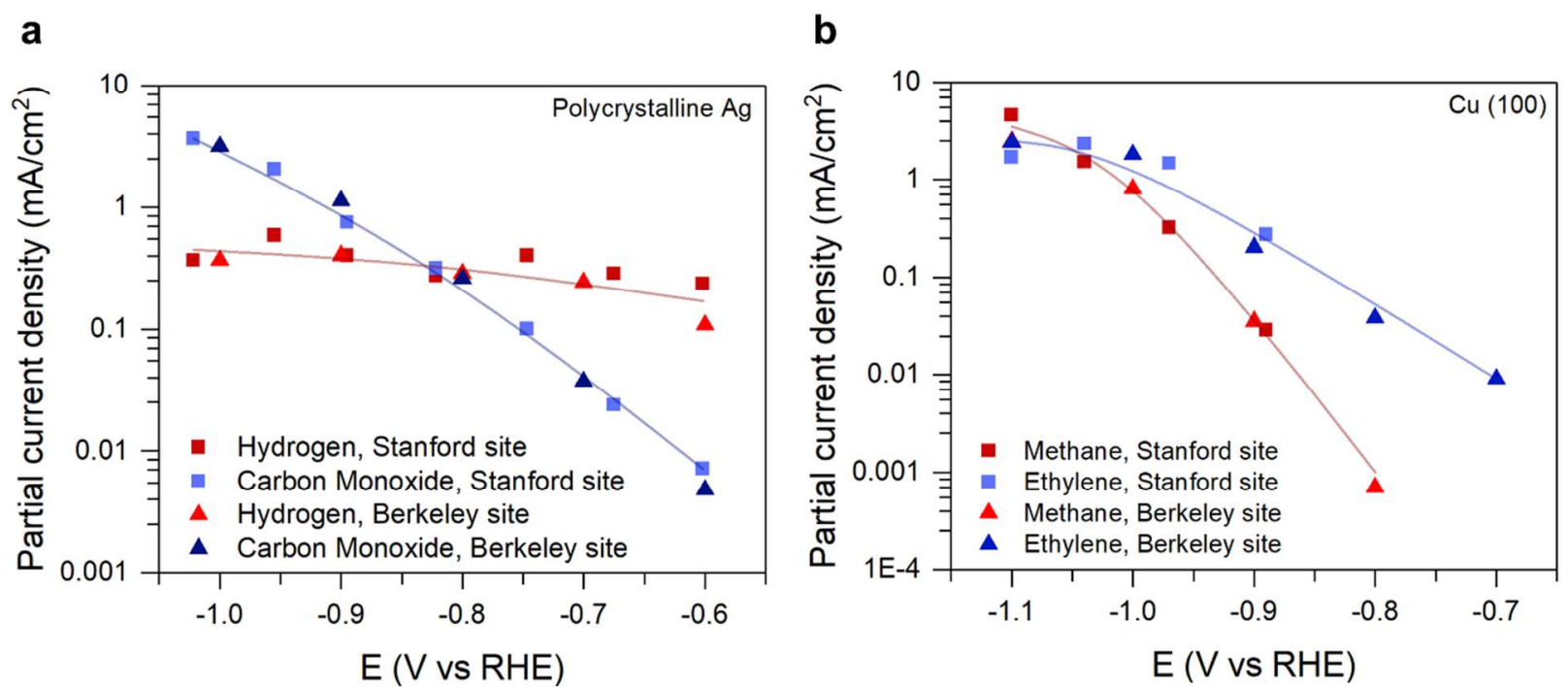

Figure 7: Interinstitutional reproducibility of benchmark catalytic activity. Observed electrocatalytic activity over electrocatalysts independently prepared and tested at two different academic institutions in $0.1 \mathrm{M} \mathrm{KHCO}_{3}$ : a) polycrystalline $\mathrm{Ag}$ and b) $\mathrm{Cu}(100)$ thin films.

\section{V: Reporting Electrocatalytic Activity}

Several figures of merit that can be utilized to report electrocatalytic activity and selectivity. One commonly used metric for selectivity is Faradaic efficiency, which is defined as the fraction of Faradaic charge utilized to produce a given product. While Faradaic efficiency is useful for describing the selectivity of a catalyst, it is problematic when comparing catalysts with drastically different activities. For example, it is tempting to conclude that the catalyst that is more selective for producing a specific product is more active for producing that product. However, an increase in selectivity to a product may or may not be accompanied by an increase in the rate at which that product is produced. In these cases, only comparing Faradaic efficiencies can obscure the true differences between two catalysts. The rate of product production, which is proportional to its partial current density, is a much less ambiguous descriptor of catalytic activity. Figure 8 compares the Faradaic efficiencies and partial current densities observed over $\mathrm{Cu}(100)$ as a function of the alkali cation in $0.1 \mathrm{M}$ bicarbonate electrolytes. ${ }^{23}$ The trends in 
Faradaic efficiency exhibit a decrease in selectivity to HER as the size of the alkali metal cation increases. Based on this metric alone, one might conclude that larger cations suppress HER. However, Figure $8 \mathrm{~b}$ shows that the rate of HER is unaffected by the identity of the electrolyte cation, as the decrease in selectivity is accompanied by an increase in the total current density. This example demonstrates that only comparing Faradaic efficiencies can give an incomplete picture of catalyst performance, and in some cases can even provide a qualitatively incorrect

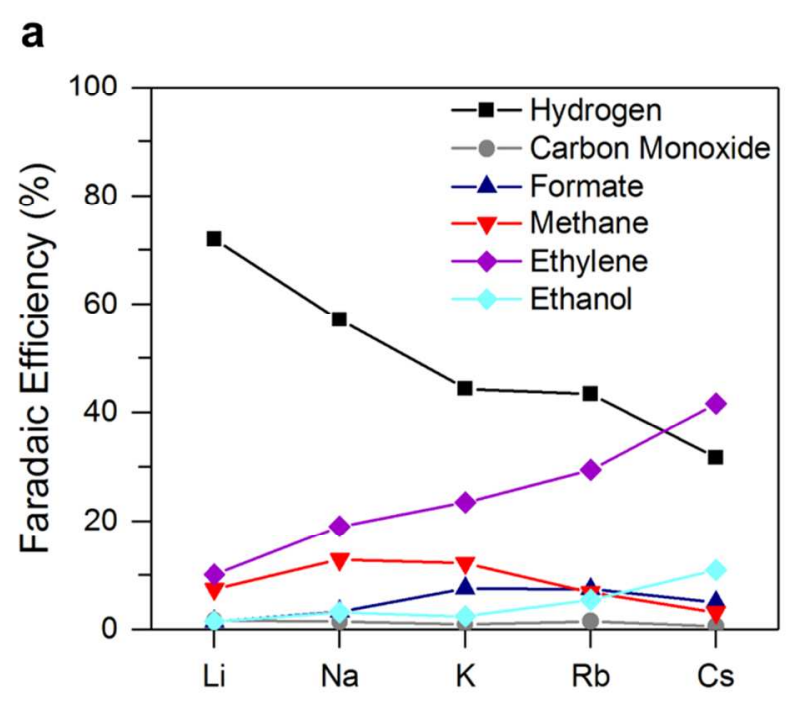

Electrolyte Cation b

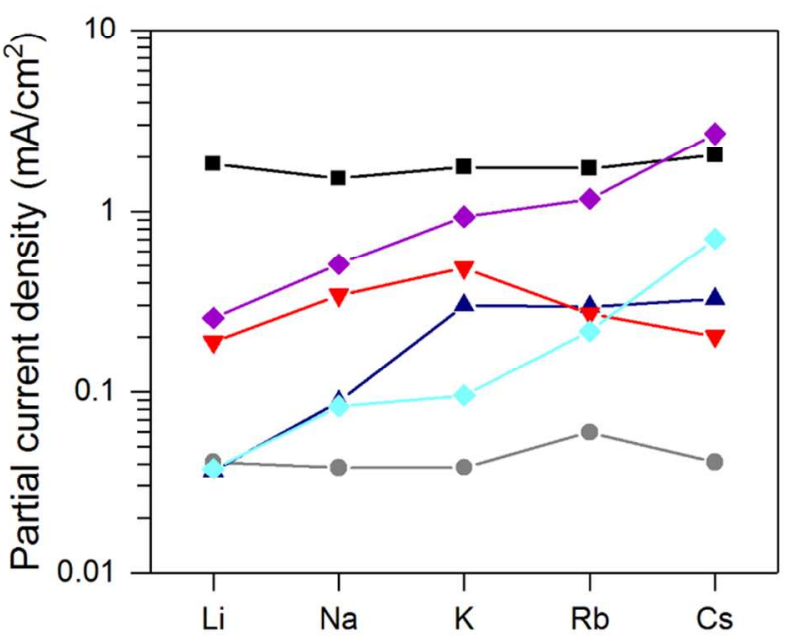

Electrolyte Cation

description of catalytic behavior as properties of the system change.

Figure 8: Comparison of Faradaic efficiencies and partial current densities. Electrocatalytic activity observed over $\mathrm{Cu}(100)$ at an applied potential of $-1 \mathrm{~V}$ vs RHE in $0.1 \mathrm{M}$ bicarbonate electrolytes as a function of the alkali cation: a) Faradaic efficiencies and b) Partial current densities.

Measured rates must be normalized by the number of available catalytic sites when making comparisons between different catalysts. ${ }^{50}$ For thermally activated reactions, and for other well studied electrocatalytic reactions, it is common to normalize observed rates by the number of active sites. ${ }^{51-54}$ This procedure has not yet been adopted for $\mathrm{CO}_{2}$ reduction, and catalytic activity is typically reported on the basis of the geometric area of the cathode. This is 
problematic because it makes it difficult to determine if reported activity improvements are the result of intrinsic activity improvements or simply higher catalyst surface area. While normalization to the number of active sites is a preferable metric it can be difficult to identify what the active site is. However, normalizing the measured activity by the electrochemically active surface area is a straightforward way to normalize catalytic activity that is meaningful and applicable to a wide variety of different electrocatalysts. ${ }^{55}$

The electrochemically active surface area (ECSA) of a electrocatalytic material can be estimated by measuring the double-layer capacitance of the electrode-electrolyte interface. ${ }^{56}$ The double layer capacitance can be measured by conducting cyclic voltammetry (CV) in a potential range where no Faradaic processes occur, typically a $100 \mathrm{mV}$ window centered at the opencircuit potential (OCP). In this potential region, any measured current can be ascribed to the nonFaradaic process of charging the electrochemical double layer. The charging current, $\mathrm{i}_{\mathrm{c}}$, measured during $\mathrm{CV}$ is related linearly to the scan rate $v$ with a slope equal to the double layer capacitance:

$$
C_{D L}=\frac{i_{c}}{v}
$$

This measured capacitance $\left(\mathrm{C}_{\mathrm{DL}}\right)$ can be compared to that of a smooth planar surface $\left(\mathrm{C}_{\mathrm{REF}}\right)$ to obtain a relative roughness factor for the electrocatalyst.

$$
E S C A=\frac{C_{D L}}{C_{R E F}}
$$

Since the reference sample is unlikely to be atomically flat and/or have the same surface termination as the sample of interest, comparisons on this basis or using a published reference capacitance value may not give accurate absolute values for the total surface area of the catalyst. However, this is generally acceptable since differences between a novel catalyst and a well- 
known benchmark are typically of interest. However, it is important to realize that in some cases the entire surface area of the electrode is not electrocatalytically active. As a result, normalizing the measured activity by the total ECSA would be inappropriate. One example is when nanoparticles are supported on an inert support, such as GC or Toray paper. For these systems underpotential deposition can give a more accurate estimate of the catalytically relevant surface area. However, this approach is dependent on the elemental composition of the electrocatalyst and must be tailored to fit the application.

The importance of reporting current densities normalized to the ECSA is illustrated in Figure 9, which compares the $\mathrm{CO}_{2}$ reduction activity observed over two polycrystalline Ag electrodes with different roughness factors. The first sample was polished mechanically while the second was roughened by electrochemical cycling in $1 \mathrm{M} \mathrm{KCl}$. Figure 9a shows that the geometric CO partial current densities of the electrodes vary by nearly an order of magnitude. However, the electrocatalysts also exhibit drastically different surface areas (see SI-8). As a result, when the $\mathrm{CO}$ partial current densities are normalized by the ECSA the catalysts are identical at low overpotentials (Figure 9b). At high overpotentials, the relatively smooth Ag catalyst performs better because mass transfer is limiting the supply of $\mathrm{CO}_{2}$ to the roughened electrode. The effects of mass transfer can be mitigated by increasing the $\mathrm{CO}_{2}$ flow rate, thereby increasing the potential window over which the two samples show identical activity. These data suggest that differences in ECSA do not lead to differences in the intrinsic activity in this case. This example highlights the importance of proper data treatment and normalization, as comparisons solely based on Faradaic efficiency or geometric partial current densities can be misleading. These results also demonstrate that care should be taken in using onset potential as a 
b

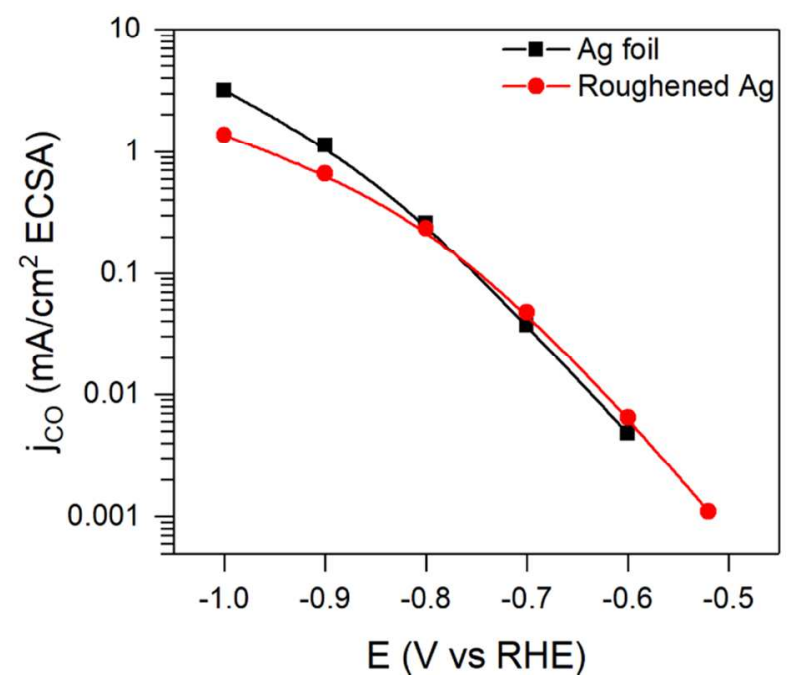

Figure 9: Surface area normalization for Ag catalysts CO partial current densities observed over a mechanically polished and electrochemically roughened $\mathrm{Ag}$ foil in $0.1 \mathrm{M} \mathrm{KHCO}_{3}$ normalized to: a) Geometric area and b) Electrochemically active surface area (ECSA).

The ECSA-normalized $\mathrm{CO}$ evolution activities of Au-based electrocatalysts have recently been compared, leading to the conclusion that no Au-based catalyst formulation reported in the literature exhibits a superior activity to polycrystalline Au foils. ${ }^{57}$ There has also been substantial interest in high surface area $\mathrm{Cu}$-based catalysts for $\mathrm{CO}_{2}$ reduction, and in particular those derived from the reduction of oxidized $\mathrm{Cu} .^{4,7,58-64}$ It has been reported that pre-oxidized $\mathrm{Cu}$ catalysts exhibit an exceptionally high activity for producing multi-carbon products, such as $\mathrm{C}_{2} \mathrm{H}_{4}$ and $\mathrm{C}_{2} \mathrm{H}_{5} \mathrm{OH}$. These studies have stimulated efforts aimed at understanding the origin of the seemingly superior catalytic activity of these oxide-derived catalysts compared to polycrystalline $\mathrm{Cu}$ foils. ${ }^{65-72}$ However it has not been clearly demonstrated if the enhanced activity is due to an increase in the total surface area of the catalyst or to an enhancement of the intrinsic activity. ${ }^{61-68}$ Using the metrics discussed above, we show in Figure 10 an example of an activity comparison 
between $\mathrm{Cu}$ standards (polycrystalline $\mathrm{Cu}$ foil and epitaxial $\mathrm{Cu}$ thin films) and a plasma treated $\mathrm{Cu}$ catalyst for which surface area measurements are available. ${ }^{7}$ We see that the ECSAnormalized partial currents for $\mathrm{C}_{2} \mathrm{H}_{4}$, the most abundant multi-carbon product produced by $\mathrm{Cu}$, reported for this high surface area electrocatalyst are comparable to those observed over polycrystalline $\mathrm{Cu}$ and $\mathrm{Cu}(100)$, indicating that the intrinsic activity of this electrocatalyst for producing multi-carbon products is not significantly affected by the way in which the catalyst is prepared. A more extensive comparison of high surface area Cu catalysts is shown in Figure S9, from which the same conclusion can be drawn (see SI-8). The different methods of producing $\mathrm{Cu}$ catalysts may result in preferential exposure of different low Miller index planes, as the variation in the data is similar to the differences in activity of $\mathrm{Cu}(111)$ and $\mathrm{Cu}(100)$; however, there is no evidence that these preparations yield sites substantially more active for producing $\mathrm{C}_{2} \mathrm{H}_{4}$ than those present on these two facets.

Although high surface area $\mathrm{Cu}$ catalysts do not show higher intrinsic activity for multicarbon product formation than polycrystalline $\mathrm{Cu}$ foils, their selectivity to these products is generally higher. In Figure $10 \mathrm{~b}$ we show the specific partial current for producing $\mathrm{H}_{2}$ over the same $\mathrm{Cu}$-base catalysts analyzed above. We see that the normalized rate of HER is lower on the high surface area electrocatalyst relative to planar $\mathrm{Cu}$ foil and $\mathrm{Cu}(100)$, especially at low overpotentials. A similar trend is observed in general in Fig S7b. A lower per site rate for HER with a constant rate of multi-carbon product formation leads to a higher selectivity to the multicarbon products. This reduced rate of HER could be the result of intrinsic differences in reactivity between the catalysts. However, it is also possible that the lower rates of HER on high surface area catalysts relative to polycrystalline $\mathrm{Cu}$ is a consequence of other differences, e.g. mass transport effects, or a smaller fraction of surface sites being covered by electrolyte 

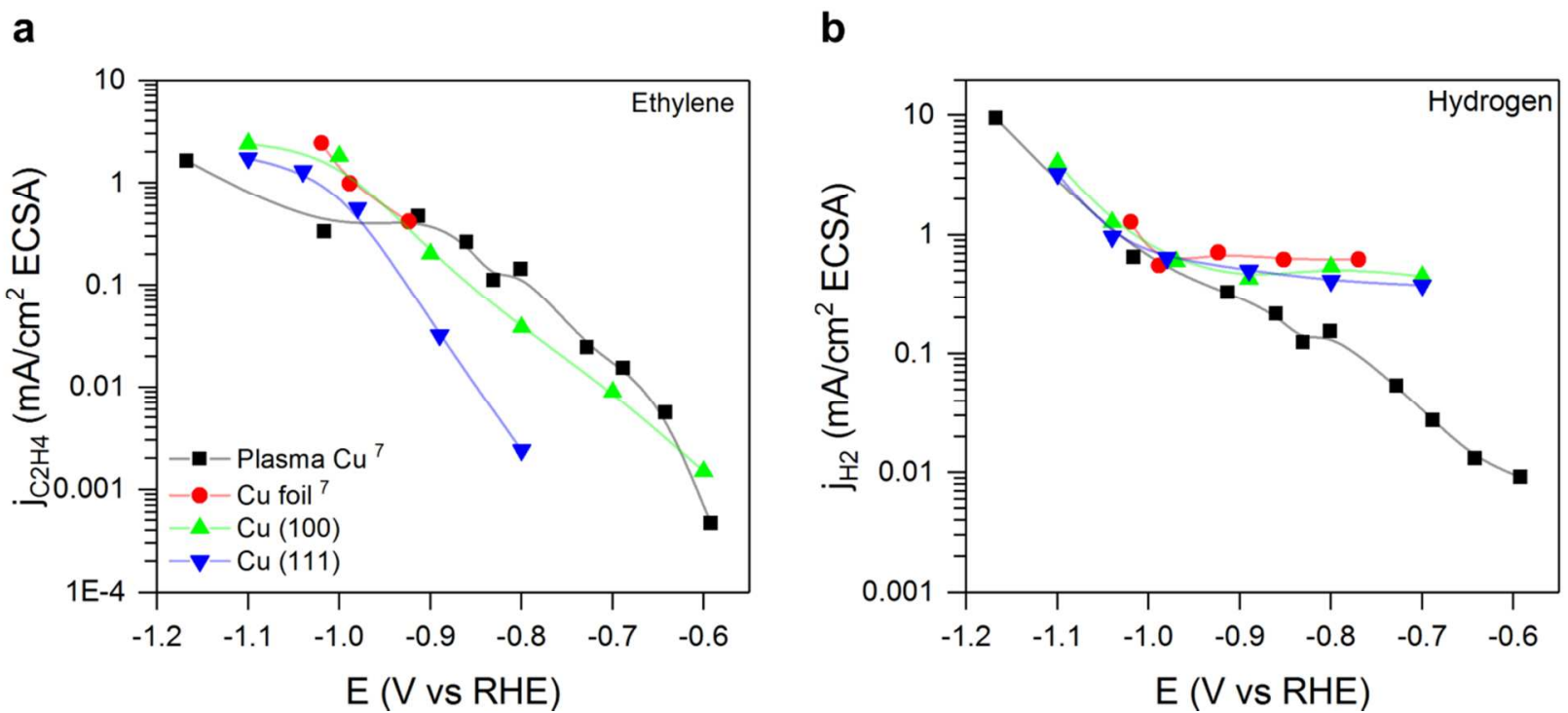

Figure 10: Comparison of ECSA-normalized activity of $\mathbf{C u}$. Surface area normalized partial currents for a) $\mathrm{C}_{2} \mathrm{H}_{4}$ and b) $\mathrm{H}_{2}$ over a plasma treated $\mathrm{Cu}$ catalyst compared to polycrystalline $\mathrm{Cu}$ foil and oriented $\mathrm{Cu}$ thin films. Data from Mistry et $\mathrm{al}^{7}$

\section{Conclusions}

In this perspective, we have demonstrated that standardizing the methods used to measure and report electrocatalytic data can aid research efforts aimed at developing novel catalysts for $\mathrm{CO}_{2}$ reduction. We recommend that catalyst activity and selectivity be measured under conditions which do not introduce artifacts from metallic impurities originating from either the electrolyte or a metallic counter electrode. Furthermore, to understand the behavior of the catalyst itself, the measured data should be taken under conditions in which rates are not a convolution of intrinsic kinetics and the effects of mass transport. Finally, catalytic data should 
be reported as rates normalized to the electrochemically active area or some specific measure of geometric active site. Adoption of the recommendations presented in this perspective would greatly facilitate meaningful comparisons of catalysts between different research groups and would facilitate the advancement of the field.

\section{Supporting Information}

Description of experimental methods, XPS and LEIS of $\mathrm{Cu}$ foils prepared via mechanical polishing, experimental protocol for quantifying the hydrodynamic boundary layer thickness of an electrochemical cell, XPS and LEIS analysis of tested electrodes, impact of electrochemical cell hydrodynamics on the measured activity of polycrystalline Ag, details of impurity sensitivity calculation, experimental protocol for quantifying the relative electrode roughness by capacitive cycling, comparison of ECSA-normalized activities of published $\mathrm{Cu}$-based catalysts.

\section{Acknowledgements}

This material is based upon work performed by the Joint Center for Artificial Photosynthesis, a DOE Energy Innovation Hub, supported through the Office of Science of the U.S. Department of Energy under Award Number DE-SC0004993. E.L.C. and J.R. were supported by the National Science Foundation (NSF).

\section{References}

1. Lewis, N. S.; Nocera, D. G. Powering the Planet: Chemical Challenges in Solar Energy Utilization. Proc. Natl. Acad. Sci. 2006, 103, 15729-15735. 
2. Chu, S.; Majumdar, A. Opportunities and Challenges for a Sustainable Energy Future.

Nature 2012, 488, 294-303.

3. Seh, Z. W.; Kibsgaard, J.; Dickens, C. F.; Chorkendorff, I.; Nørskov, J. K.; Jaramillo, T.

F. Combining Theory and Experiment in Electrocatalysis: Insights into Materials Design.

Science 2017, 355, 1-12.

4. Li, C.; Kanan, M. $\mathrm{CO}_{2}$ Reduction at Low Overpotential on $\mathrm{Cu}$ Electrodes Resulting from the Reduction of Thick $\mathrm{Cu}_{2} \mathrm{O}$ Films. J. Am. Chem. Soc. 2012, 134, 7231-7234.

5. Kim, D.; Resasco, J.; Yu, Y.; Asiri, A. M.; Yang, P. Synergistic Geometric and Electronic Effects for Electrochemical Reduction of Carbon Dioxide using Gold-Copper Bimetallic Nanoparticles. Nat. Commun. 2014, 5, 1-8.

6. Lu, Q.; Rosen, J.; Zhou, Y.; Hutchings, G. S.; Kimmel, Y. C.; Chen, J. G.; Jiao, F. A Selective and Efficient Electrocatalyst for Carbon Dioxide Reduction. Nat. Commun. 2014, 5, 16.

7. Mistry, H.; Varela, A. S.; Bonifacio, C. S.; Zegkinoglou, I.; Sinev, I.; Choi, Y.-W.;

Kisslinger, K.; Stach, E. A.; Yang, J. C.; Strasser, P.; Cuenya, B. R. Highly Selective PlasmaActivated Copper Catalysts for Carbon Dioxide Reduction to Ethylene. Nat. Commun. 2016, 7 , 1-9.

8. Kortlever, R.; Shen, J.; Schouten, K. J. P.; Calle-Vallejo, F.; Koper, M. T. M. Catalysts and Reaction Pathways for the Electrochemical Reduction of Carbon Dioxide. J. Phys. Chem. Lett. 2015, 6, 4073-4082.

9. Qiao, J.; Liu, Y.; Hong, F.; Zhang, J. A Review of Catalysts for the Electroreduction of Carbon Dioxide to Produce Low-Carbon Fuels. Chem. Soc. Rev. 2014, 43, 631-675. 
10. Costentin, C.; Robert, M.; Saveant, J.-M. Catalysts for the Electrochemical Reduction of Carbon Dioxide. Chem. Soc. Rev. 2013, 42, 2423-2436.

11. Hori, Y.; Vayenas, C.; White, R.; Gamboa Aldeco, M. Electrochemical $\mathrm{CO}_{2}$ Reduction on Metal Electrodes In Modern Aspects of Electrochemistry, Springer: New York, 2008; 42, 89189.

12. Kuhl, K.; Cave, E.; Abram, D.; Jaramillo, T. New Insights into the Electrochemical Reduction of Carbon Dioxide on Metallic Copper Surfaces. Energy Environ. Sci. 2012, 5, 70507059.

13. Hori, Y.; Wakebe, H.; Tsukamoto, T.; Koga, O. Adsorption of CO Accompanied with Simultaneous Charge-Transfer on Copper Single-Crystal Electrodes Related with Electrochemical Reduction of $\mathrm{CO}_{2}$ to Hydrocarbons. Surf. Sci. 1995, 335, 258-263.

14. Reske, R.; Mistry, H.; Behafarid, F.; Cuenya, B.; Strasser, P. Particle Size Effects in the Catalytic Reduction of $\mathrm{CO}_{2}$ on Cu Nanoparticles. J. Am. Chem. Soc. 2014, 136, 6978-6986.

15. Hori, Y.; Takahashi, I.; Koga, O.; Hoshi, N. Selective Formation of C2 Compounds from Electrochemical Reduction of $\mathrm{CO}_{2}$ at a Series of Copper Single Crystal Electrodes. J. Phys. Chem. B 2002, 106, 15-17.

16. Hahn, C.; Hatsukade, T.; Kim, Y.; Vailionis, A.; Baricuatro, J.; Higgins, D.; Nitopi, S.; Soriaga, M.; Jaramillo, T. Engineering Cu Surfaces for the Electrocatalytic Conversion of $\mathrm{CO}_{2}$ : Controlling Selectivity toward Oxygenates and Hydrocarbons. Proc. Natl. Acad. Sci. 2017, 114, 5918-5923.

17. Hoshi, N.; Kato, M.; Hori, Y. Electrochemical Reduction of $\mathrm{CO}_{2}$ on Single Crystal Electrodes of Silver Ag(111), Ag(100) and Ag(110). J. Electroanal. Chem. 1997, 440, 283-286. 
18. Hatsukade, T.; Kuhl, K.; Cave, E.; Abram, D.; Jaramillo, T. Insights into the Electrocatalytic Reduction of $\mathrm{CO}_{2}$ on Metallic Silver Surfaces. Phys. Chem. Chem. Phys. 2014, $16,13814-13819$.

19. Tang, W.; Peterson, A.; Varela, A.; Jovanov, Z.; Bech, L.; Durand, W.; Dahl, S.; Norskov, J.; Chorkendorff, I. The Importance of Surface Morphology in Controlling the Selectivity of Polycrystalline Copper for $\mathrm{CO}_{2}$ Electroreduction. Phys. Chem. Chem. Phys. 2012, $14,76-81$.

20. Terunuma, Y.; Saitoh, A.; Momose, Y. Relationship Between Hydrocarbon Production in the Electrochemical Reduction of $\mathrm{CO}_{2}$ and the Characteristics of the $\mathrm{Cu}$ Electrode. $J$. Electroanal. Chem. 1997, 434, 69-75.

21. Vijh, A. K. Electrolytic hydrogen evolution reaction on aluminum, oxide-covered electrodes. J. Phys. Chem. 1969, 73, 506-513.

22. Akira, M.; Yoshio, H. Product Selectivity Affected by Cationic Species in Electrochemical Reduction of $\mathrm{CO}_{2}$ and $\mathrm{CO}$ at a $\mathrm{Cu}$ Electrode. Bull. Chem. Soc. Jpn. 1991, 64, $123-127$.

23. Resasco, J.; Chen, L.; Clark, E.; Tsai, C.; Hahn, C.; Jaramillo, T.; Chan, K.; Bell, A. Promoter Effects of Alkali Metal Cations on the Electrochemical Reduction of Carbon Dioxide. J. Am. Chem. Soc. 2017, 139, 11277-11287.

24. Hori, Y.; Murata, A.; Takahashi, R. Formation of Hydrocarbons in the Electrochemical Reduction of Carbon Dioxide at a Copper Electrode in Aqueous Solution. J. Chem. Soc. Faraday Trans. I 1989, 85, 2309-2326. 
25. Varela, A. S.; Kroschel, M.; Reier, T.; Strasser, P. Controlling the Selectivity of $\mathrm{CO}_{2}$ Electroreduction on Copper: The Effect of Electrolyte Concentration and the Importance of the Local pH. Catal. Today 2016, 260, 8-13.

26. Kas, R.; Kortlever, R.; Yılmaz, H.; Koper, M. T. M.; Mul, G. Manipulating the Hydrocarbon Selectivity of Copper Nanoparticles in $\mathrm{CO}_{2}$ Electroreduction by Process Conditions. ChemElectroChem 2015, 2, 354-358.

27. Resasco, J.; Lum, Y.; Clark, E. L.; Zeledon, J. Z.; Bell, A. T. Effects of Anion Identity and Concentration on Electrochemical Reduction of $\mathrm{CO}_{2}$. ChemElectroChem. 2018, 5, 10641072.

28. Butler, J. N., The Basic Equations In Carbon dioxide equilibria and their applications. Addison-Wesley series in Civil Engineering; Addison-Wesley: Reading, Mass. 1982, 1, 15-43. 29. Haynes, W. M., Ed. Diffusion of Gases in Water In Handbook of chemistry and physics. $94^{\text {th }}$ Edition, CRC press: Boca Raton, FL. 2014, 6-250.

30. Singh, M. R.; Clark, E. L.; Bell, A. T. Effects of Electrolyte, Catalyst, and Membrane Composition and Operating Conditions on the Performance of Solar-Driven Electrochemical Reduction of Carbon Dioxide. Phys. Chem. Chem. Phys. 2015, 17, 18924-18936.

31. Gupta, N.; Gattrell, M.; MacDougall, B. Calculation for the Cathode Surface Concentrations in the Electrochemical Reduction of $\mathrm{CO}_{2}$ in $\mathrm{KHCO}_{3}$ Solutions. J. Appl. Electrochem. 2006, 36, 161-172.

32. Lobaccaro, P.; Singh, M. R.; Clark, E. L.; Kwon, Y.; Bell, A. T.; Ager, J. W. Effects of Temperature and Gas-Liquid Mass Transfer on the Operation of Small Electrochemical Cells for the Quantitative Evaluation of $\mathrm{CO}_{2}$ Reduction Electrocatalysts. Phys. Chem. Chem. Phys. 2016, 18, 26777-26785. 
33. Clark, E. L.; Singh, M. R.; Kwon, Y.; Bell, A. T. Differential Electrochemical Mass Spectrometer Cell Design for Online Quantification of Products Produced During Electrochemical Reduction of $\mathrm{CO}_{2}$. Anal. Chem. 2015, 87, 8013-8020.

34. Dunwell, M.; Yang, X.; Setzler, B. P.; Anibal, J.; Yan, Y.; Xu, B.; Examination of NearElectrode Concentration Gradients and Kinetic Impacts on the Electrochemical Reduction of $\mathrm{CO}_{2}$ using Surface-Enhanced Infrared Spectroscopy. ACS Catal. 2018, 8, 3999-4008.

35. Clark, E. L.; Bell, A. T. Direct Observation of the Local Reaction Environment during the Electrochemical Reduction of $\mathrm{CO}_{2} . J$. Am. Chem. Soc. Just Accepted Manuscript. DOI: $10.1021 /$ jacs. 8 b04058

36. Butt, J. B.; Petersen, E. E., Physical \& Chemical Description of Deactivation In Activation, Deactivation, and Poisoning of Catalysts, Academic Press Inc.: San Diego, 1988, 425.

37. Kuhl, K. P.; Hatsukade, T.; Cave, E. R.; Abram, D. N.; Kibsgaard, J.; Jaramillo, T. F. Electrocatalytic Conversion of Carbon Dioxide to Methane and Methanol on Transition Metal Surfaces. J. Am. Chem. Soc. 2014, 136, 14107-14113.

38. Hori, Y.; Konishi, H.; Futamura, T.; Murata, A.; Koga, O.; Sakurai, H.; Oguma, K. "Deactivation of Copper Electrode" in Electrochemical Reduction of $\mathrm{CO}_{2}$. Electrochim. Acta 2005, 50, 5354-5369.

39. Wuttig, A.; Surendranath, Y. Impurity Ion Complexation Enhances Carbon Dioxide Reduction Catalysis. ACS Catal. 2015, 5, 4479-4484.

40. Seah, M. P.; Dench, W. A. Quantitative Electron Spectroscopy of Surfaces: A Standard Data Base for Electron Inelastic Mean Free Paths in Solids. Surf. Interface Anal. 1979, 1, 2-11. 
41. Shard, A. G. Detection Limits in Xps for More Than 6000 Binary Systems Using Al and Mg Ka X-Rays. Surf. Interface Anal. 2014, 46, 175-185.

42. Cushman, C. V.; Bruner, P.; Zakel, J.; Major, G. H.; Lunt, B. M.; Smith, N. J.; Grehl, T.; Linford, M. R. Low Energy Ion Scattering (LEIS). A Practical Introduction to Its Theory, Instrumentation, and Applications. Anal. Methods 2016, 8, 3419-3439.

43. Lopes, P. P.; Strmcnik, D.; Tripkovic, D.; Connell, J. G.; Stamenkovic, V.; Markovic, N. M. Relationships between Atomic Level Surface Structure and Stability/Activity of Platinum Surface Atoms in Aqueous Environments. ACS Catal. 2016, 6, 2536-2544.

44. Chen, R.; Yang, C.; Cai, W.; Wang, H.-Y.; Miao, J.; Zhang, L.; Chen, S.; Liu, B. Use of Platinum as the Counter Electrode to Study the Activity of Nonprecious Metal Catalysts for the Hydrogen Evolution Reaction. ACS Energy Lett. 2017, 2, 1070-1075.

45. Dong, G.; Fang, M.; Wang, H.; Yip, S.; Cheung, H.-Y.; Wang, F.; Wong, C.-Y.; Chu, S. T.; Ho, J. C. Insight into the Electrochemical Activation of Carbon-Based Cathodes for Hydrogen Evolution Reaction. J. Mater. Chem. A 2015, 3, 13080-13086.

46. Cherevko, S.; Zeradjanin, A. R.; Topalov, A. A.; Kulyk, N.; Katsounaros, I.; Mayrhofer, K. J. J. Dissolution of Noble Metals During Oxygen Evolution in Acidic Media. ChemCatChem 2014, 6, 2219-2223.

47. Cherevko, S.; Zeradjanin, A. R.; Keeley, G. P.; Mayrhofer, K. J. J. A Comparative Study on Gold and Platinum Dissolution in Acidic and Alkaline Media. J. Electrochem. Soc. 2014, 161, $822-830$.

48. Chen, J. G.; Jones, C. W.; Linic, S.; Stamenkovic, V. R. Best Practices in Pursuit of Topics in Heterogeneous Electrocatalysis. ACS Catal. 2017, 7, 6392-6393. 
49. Dunwell, M.; Lu, Q.; Heyes, J. M.; Rosen, J.; Chen, J. G.; Yan, Y.; Jiao, F.; Xu, B. The Central Role of Bicarbonate in the Electrochemical Reduction of Carbon Dioxide on Gold. $J$. Am. Chem. Soc. 2017, 139, 3774-3783.

50. Boudart, M. Turnover Rates in Heterogeneous Catalysis. Chem. Rev. 1995, 95, 661-666.

51. Gasteiger, H. A.; Kocha, S. S.; Sompalli, B.; Wagner, F. T. Activity Benchmarks and Requirements for Pt, Pt-Alloy, and Non-Pt Oxygen Reduction Catalysts for PEMFCs. Appl. Catal. B: Environ. 2005, 56, 9-35.

52. McCrory, C. C. L.; Jung, S.; Peters, J. C.; Jaramillo, T. F. Benchmarking Heterogeneous Electrocatalysts for the Oxygen Evolution Reaction. J. Am. Chem. Soc. 2013, 135, 16977-16987. 53. McCrory, C. C. L.; Jung, S.; Ferrer, I. M.; Chatman, S. M.; Peters, J. C.; Jaramillo, T. F. Benchmarking Hydrogen Evolving Reaction and Oxygen Evolving Reaction Electrocatalysts for Solar Water Splitting Devices. J. Am. Chem. Soc. 2015, 137, 4347-4357.

54. Bligaard, T.; Bullock, R. M.; Campbell, C. T.; Chen, J. G.; Gates, B. C.; Gorte, R. J.; Jones, C. W.; Jones, W. D.; Kitchin, J. R.; Scott, S. L. Toward Benchmarking in Catalysis Science: Best Practices, Challenges, and Opportunities. ACS Catal. 2016, 6, 2590-2602.

55. Benck, J. D.; Hellstern, T. R.; Kibsgaard, J.; Chakthranont, P.; Jaramillo, T. F. Catalyzing the Hydrogen Evolution Reaction (HER) with Molybdenum Sulfide Nanomaterials. ACS Catal. 2014, 4, 3957-3971.

56. Trasatti, S.; Petrii, O. A., Real surface area measurements in electrochemistry. Pure Appl. Chem., 1991; 63, 711-734.

57. Jovanov, Z. P.; Hansen, H. A.; Varela, A. S.; Malacrida, P.; Peterson, A. A.; Nørskov, J. K.; Stephens, I. E. L.; Chorkendorff, I. Opportunities and challenges in the electrocatalysis of 
$\mathrm{CO}_{2}$ and $\mathrm{CO}$ reduction using bifunctional surfaces: A theoretical and experimental study of AuCd alloys. J. Catal. 2016, 343, 215-231.

58. Chen, Y.; Li, C. W.; Kanan, M. W. Aqueous $\mathrm{CO}_{2}$ Reduction at Very Low Overpotential on Oxide-Derived Au Nanoparticles. J. Am. Chem. Soc. 2012, 134, 19969-19972.

59. Chen, Y.; Kanan, M. W. Tin Oxide Dependence of the $\mathrm{CO}_{2}$ Reduction Efficiency on Tin Electrodes and Enhanced Activity for Tin/Tin Oxide Thin-Film Catalysts. J. Am. Chem. Soc. 2012, 134, 1986-1989.

60. Roberts, F. S.; Kuhl, K. P.; Nilsson, A. Electroreduction of Carbon Monoxide over a Copper Nanocube Catalyst: Surface Structure and pH Dependence on Selectivity. ChemCatChem 2016, 8, 1119-1124.

61. Kwon, Y.; Lum, Y.; Clark, E. L.; Ager, J. W.; Bell, A. T. $\mathrm{CO}_{2}$ Electroreduction with Enhanced Ethylene and Ethanol Selectivity by Nanostructuring Polycrystalline Copper.

ChemElectroChem 2016, 3, 1012-1019.

62. Ma, M.; Djanashvili, K.; Smith, W. A. Controllable Hydrocarbon Formation from the Electrochemical Reduction of $\mathrm{CO}_{2}$ over Cu Nanowire Arrays. Angew. Chem. Int. Ed. 2016, 55, 6680-6684.

63. Ren, D.; Deng, Y.; Handoko, A. D.; Chen, C. S.; Malkhandi, S.; Yeo, B. S. Selective Electrochemical Reduction of Carbon Dioxide to Ethylene and Ethanol on Copper(I) Oxide Catalysts. ACS Catal. 2015, 5, 2814-2821.

64. Raciti, D.; Livi, K. J.; Wang, C. Highly Dense Cu Nanowires for Low-Overpotential $\mathrm{CO}_{2}$ Reduction. Nano Lett. 2015, 15, 6829-6835.

65. Verdaguer-Casadevall, A.; Li, C. W.; Johansson, T. P.; Scott, S. B.; McKeown, J. T.; Kumar, M.; Stephens, I. E. L.; Kanan, M. W.; Chorkendorff, I. Probing the Active Surface Sites 
for CO Reduction on Oxide-Derived Copper Electrocatalysts. J. Am. Chem. Soc. 2015, 137, 9808-9811.

66. Feng, X.; Jiang, K.; Fan, S.; Kanan, M. W. A Direct Grain-Boundary-Activity Correlation for CO Electroreduction on Cu Nanoparticles. ACS Cent. Sci. 2016, 2, 169-174.

67. Gao, D.; Zegkinoglou, I.; Divins, N. J.; Scholten, F.; Sinev, I.; Grosse, P.; Roldan

Cuenya, B. Plasma-Activated Copper Nanocube Catalysts for Efficient Carbon Dioxide

Electroreduction to Hydrocarbons and Alcohols. ACS Nano 2017, 11, 4825-4831.

68. Cheng, T.; Xiao, H.; Goddard, W. A. Nature of the Active Sites for CO Reduction on Copper Nanoparticles; Suggestions for Optimizing Performance. J. Am. Chem. Soc. 2017, 139, $11642-11645$.

69. Favaro, M.; Xiao, H.; Cheng, T.; Goddard, W. A.; Yano, J.; Crumlin, E. J. Subsurface Oxide Plays a Critical Role in $\mathrm{CO}_{2}$ Activation by $\mathrm{Cu}(111)$ Surfaces to Form Chemisorbed $\mathrm{CO}_{2}$, the First Step in Reduction of $\mathrm{CO}_{2}$. Proc. Natl. Acad. Sci. 2017, 114, 6706-6711.

70. Cavalca, F.; Ferragut, R.; Aghion, S.; Eilert, A.; Diaz-Morales, O.; Liu, C.; Koh, A. L.; Hansen, T. W.; Pettersson, L. G. M.; Nilsson, A. Nature and Distribution of Stable Subsurface Oxygen in Copper Electrodes During Electrochemical $\mathrm{CO}_{2}$ Reduction. J. Phys. Chem. C 2017, $121,25003-25009$.

71. Eilert, A.; Cavalca, F.; Roberts, F. S.; Osterwalder, J.; Liu, C.; Favaro, M.; Crumlin, E. J.; Ogasawara, H.; Friebel, D.; Pettersson, L. G. M.; Nilsson, A. Subsurface Oxygen in OxideDerived Copper Electrocatalysts for Carbon Dioxide Reduction. J. Phys. Chem. Lett. 2017, 8, 285-290. 
72. Liu, C.; Lourenço, M. P.; Hedström, S.; Cavalca, F.; Diaz-Morales, O.; Duarte, H. A.; Nilsson, A.; Pettersson, L. G. M. Stability and Effects of Subsurface Oxygen in Oxide-Derived $\mathrm{Cu}$ Catalyst for $\mathrm{CO}_{2}$ Reduction. J. Phys. Chem. C 2017, 121, 25010-25017. 